\title{
Calcium Excretion Rate
}

National Cancer Institute

\section{Source}

National Cancer Institute. Calcium Excretion Rate. NCI Thesaurus. Code C150815.

A determination of the amount of calcium being excreted in a biological specimen over a defined period of time. 